\title{
A Numerical Study on the Sensitivity of Soot and NOx Formation to the Operating Conditions in Heavy Duty Engines
}

Hesameddin Fatehi and Eric Wingren Lund University

Tommaso Lucchini and Gianluca D'Errico Politecnico di Milano

Anders Karlsson Volvo Group Trucks Technology

Oivind Andersson and Xue-Song Bai Lund University

Citation: Fatehi, H., Wingren, E., Lucchini, T., D'Errico, G. et al., "A Numerical Study on the Sensitivity of Soot and NOx Formation to the Operating Conditions in Heavy Duty Engines," SAE Technical Paper 2018-01-0177, 2018, doi:10.4271/2018-01-0177.

\section{Abstract}

$\mathrm{n}$ this paper, computation fluid dynamics (CFD) simulations are employed to describe the effect of flow parameters on the formation of soot and $\mathrm{NO}_{x}$ in a heavy duty engine under low load and high load. The complexity of diesel combustion, specially when soot, $\mathrm{NO}_{x}$ and other emissions are of interest, requires using a detailed chemical mechanism to have a correct estimation of temperature and species distribution. In this work, Multiple Representative Interactive Flamelets (MRIF) method is employed to describe the chemical reactions, ignition, flame propagation and emissions in the engine. A phenomenological model for soot formation, including soot nucleation, coagulation and oxidation with $\mathrm{O} 2$ and $\mathrm{OH}$ is incorporated into the flamelet combustion model. Different strategies for modelling $\mathrm{NO}_{x}$ are chosen to take into account the longer time scale for $\mathrm{NO}_{x}$ formation. The numerical results are compared with experimental data to show the validity of the model for the cases under study. A good agreement is achieved between the model results and the pressure and heat release rate from the experiment. For soot and $\mathrm{NO}_{x}$, the model is able to correctly predict the trends between different cases. The effect of number of RIFs on the behaviour of the model is discussed.

\section{Introduction}

omputational fluid dynamics (CFD) models have been proven useful for understanding the underlying physics in the internal combustion engines. Due to the presence of many complex physical and chemical processes in the compression ignition (CI) engines, accurate modelling of these combustion systems is still among the most challenging tasks for researchers and engineers. Interaction of chemistry and turbulence at high pressure and presence of multiphase flow and spray, together with formation of soot and other emissions require thoughtful modelling strategies. Using a detailed reaction mechanism for combustion of fuel in the engine simulations is necessary for having a correct prediction of ignition delay time and flame structure. Although it is possible to use global reaction mechanism and calibrate their rate constants to match the experimental data, this approach lacks the generality. On the other hand, detailed reaction mechanisms consist of hundreds of species and thousands of reactions with different time scales. Direct integration of the reaction rates in the CFD domain imposes stiffness problem on the computational models which leads to increasingly high computational cost due to the highly non-linear nature of these equations.
To tackle this issue, different approaches have been developed to reduce the cost of integrating reaction rates in the CFD simulations. A review on different techniques to accommodate large chemistry mechanism in the CFD simulations can be found in [1]. For example, by coupling of dynamic adaptive chemistry (DAC) reduction approach with in situ adaptive tabulation (ISAT) algorithm, [2] developed the tabulation of dynamic adaptive chemistry (TDAC) method to reduce the cost of chemistry mechanism particularly in unsteady simulations of internal combustion engines.

Another approach is based on mapping of the high dimensional thermochemical space into low dimensional manifolds. In this approach, few key parameters such as mixture fraction, pressure, temperature, progress variable or scalar dissipation rate represent the high dimensional chemistry space. Flamelet modelling approach proposed by $[\underline{3}, \underline{4}]$ is the most popular approach to represent turbulent combustion in numerical simulations. In this model, assuming that the turbulent time scale is much larger than the chemistry time scale, the turbulent diffusion flame is viewed as an ensemble of thin laminar reaction zones or flamelets embedded within turbulent structures. In this simplified representation of flow and chemistry interaction, the chemistry is represented 
in a low dimensional manifold characterized by mixture fraction and scalar dissipation rate.

To account for the unsteady evolution of flamelet concurrently with CFD calculations, and to provide the necessary boundary conditions and variation of mixture fraction for the one dimensional flamelets equations, the Representative Interactive Flamelet (RIF) approach has been developed and extensively tested and validated in different engine conditions [5]. The results show that the RIF approach can correctly reproduce the qualitative trends in ignition delay and heat release rate profile by altering the initial temperature and start of injection [] $]$, can capture the auto-ignition delay and location of ignition front [7] and can represent the effect of different injection strategies and EGR content on the in-cylinder pressure []. A review of the model can be found in [9]. However, due to the high shear stress created by spray, a vast distribution of scalar dissipation rate occurs throughout the domain. To take into account the spatial variation of scalar dissipation rate, Multiple Representative Interactive Flamelet (MRIF) approach is developed and tested for different conditions $[\underline{9}, \underline{10}, \underline{11}]$.

In this paper, the MRIF approach is employed to study the formation and oxidation of soot and other emissions in a direct injection compression ignition engine. The Lib-ICE code, a set of libraries and solvers for simulation of IC engines based on OpenFOAM software $[\underline{12}, \underline{13}, \underline{14}]$, is employed in this study. The Eulerian-Lagrangian approach is used to model the spray evolution with sub-models for spray breakup, atomization, collision, evaporation and dispersion. Sub-models for estimating the main pollutant emissions, namely $\mathrm{CO}, \mathrm{NO}_{x}$ and soot, are included in the model which will be discussed in the following sections. The experimental cases from a heavy duty engine are used to validate the model at different loads and different start of injection and different total injected fuel mass.

\section{Numerical Model}

As explained in the previous section, Multiple Representative Interactive Flamelet (MRIF) approach is used in this study. The model is based on the well-known flamelet approach proposed by $[\underline{3}, \underline{4}]$ and extended by many others, e.g. [ $[\underline{5}, \underline{9}]$. Based on the flamelet approach, the high dimensional thermodynamics state is reduced by a coordinate transformation to flamelet space where all the reacting scalars can be represented by mixture fraction, $Z$. By assuming that the sub-grid distribution of the $\mathrm{Z}$ is represented by a $\beta$-PDF, the local composition of chemical species can be calculated in the CFD domain. The conservation equations for species and temperature, or enthalpy, is then solved in the one-dimensional flamelet space. The effect of mixing and coupling between the flow field and chemistry is incorporated in the average of local values of scalar dissipation rate as a measure of turbulence intensity.

The mean scalar dissipation rate cannot sufficiently represent the turbulent-flow interaction in situations where high variations in spatial distribution of turbulent intensity or significant heat losses are present in the CFD domain. To account for variation of scalar dissipation rate on the history of flamelet library in the CFD domain, multiple number of flamelets, each representative of a portion of the injected fuel mass, are used. To track the flamelet representatives, a transport equation is solved for a marker for each flamelet and the species distribution in each computation cell is related to these flamelet markers by the probability of finding that marker in the cell.

The flamelet equations for species mass fraction and enthalpy with unity Lewis number assumption reads as follows,

$$
\begin{gathered}
\rho \frac{\partial Y_{i}}{\partial t}=\rho \frac{\chi_{z}}{2} \frac{\partial Y_{i}}{\partial Z^{2}}+\dot{\omega}_{i}, \\
\rho \frac{\partial h_{s}}{\partial t}=\rho \frac{\chi_{z}}{2} \frac{\partial h_{s}}{\partial Z^{2}}+\dot{q}_{s},
\end{gathered}
$$

where $Y_{i}$ is the mass fraction of species $i, \rho$ is the density, $Z$ is the mixture fraction, $\chi_{z}$ is the scalar dissipation rate, $\dot{\omega}_{i}$ is the chemical source term of species $i, h_{s}$ is the specific sensible enthalpy and $\dot{q}_{s}$ is the heat release due to chemical reactions.

The interaction between the CFD domain and the flamelet space is incorporated by averaging the stoichiometric scalar dissipation rate in the CFD domain and passing the value into the flamelet space. Then Eqn 1 and $\underline{2}$ are solved in the one-dimensional mixture fraction space. The species and enthalpy are then re-mapped into the CFD domain based on the solutions of the mixture fraction, its variance and flamelet markers equations.

Despite the fact that ordinary differential equations (ODE) imposed by detailed chemical mechanism to calculate the reaction rates of the species are solved in the one dimensional flamelet space, solution of these stiff ODEs and integration of $\beta$-PDF functions in the CFD domain requires enormous effort of calculations. To have a manageable computational time, on-line mechanism reduction and tabulation techniques are employed to reduce the number of species and reactions in the chemical mechanism. Moreover, by clustering the CFD nodes in a two dimensional space of mixture fraction and its variance, the $\beta$-PDFs are integrated in this $2 \mathrm{D}$ space and the corresponding species compositions are mapped back to the CFD domain. The details of the equations and the algorithm of flamelet-CFD interaction along with the techniques that are used to reduce the computational costs can be found in [11].

\section{Spray Model}

The spray model is based on the well established LagrangianEulerian approach where the continuum phase, gas, is treated by Eulerian system of equations and the discrete phase, liquid, is treated in the Lagrangian framework. The coupling between the two phase is provided by corresponding source terms for mass, species, momentum and energy. Parcels, group of particles with the same properties, are introduced into the domain with the size equal to the injector exit diameter. Primary breakup of the spray is considered as a result of the instabilities of the liquid jet. Both Kelvin-Helmholtz $(\mathrm{KH})$ and RayleighTaylor (RT) instabilities are taken into account (KHRT model) for the breakup [15]. KH instability is the reason for the primary breakup while the secondary breakup is initiated by $\mathrm{KH}$ instability and accelerated by RT instability. 
A predetermined length from the nozzle exit is considered in the model where the RT is only affecting the breakup after that length [16]. The standard evaporation model based on the $D^{2}$-law with mass transfer coefficient from Ranz-Marshal correlation is used to model fuel evaporation.

\section{Modelling Pollutant Emissions}

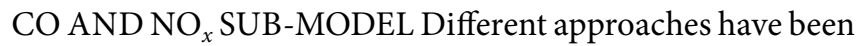
used to calculate the concentration of $\mathrm{CO}$ and $\mathrm{NO}_{x}$. For $\mathrm{CO}$, similar to other main species, the concentration is directly integrated from the $\beta$-PDFs of all the RIFs in the flamelet zone. In general, the mass fraction of species is converted from the flamelet zone into CFD domain through the following equation:

$$
Y_{i}(\vec{x})=\sum_{j=1}^{N_{f}} M_{j} \int_{0}^{1} Y_{j, i}(Z) P\left(Z, \widetilde{Z^{\prime \prime}}\right) \mathrm{d} Z,
$$

where $M_{j}$ is the marker for the flamelet $j$ and $N_{f}$ is the number of flamelets. $P$ is the probability function in the form of $\beta$-PDF. This formulation is able to capture the formation of $\mathrm{CO}$ in fuel rich zone and the transport by the flow and turbulence in lean regions where it oxidized.

For $\mathrm{NO}_{x}$, however, different approaches have been employed. First of all, $\mathrm{NO}$ is chosen to represents $\mathrm{NO}_{x}$ and the Extended Zeldovich mechanism is used to model the formation of NO [17]. Since the formation of NO has relatively larger time scale compared to other species, including the NO mechanism in the flamelet library and direct integration of its $\beta$-PDF into CFD domain leads to over-prediction of $\mathrm{NO}$ concentration. Another approach is direct integration of $\mathrm{NO}$ formation mechanism in the CFD domain by solving the transport equations for NO. In this case, the effect of temperature stratification can be captured, however, in this approach the turbulence-chemistry interaction is not considered. In the third approach used in this study, the transport equation for $\mathrm{NO}$ is solved in the CFD domain, however, the reaction rate of NO is integrated from the flamelet zone in a similar way as the Eq 3. In this approach the temperature stratification is not considered but the interaction between the chemistry and turbulence is taken into account.

SOOT SUB-MODEL The main features of the soot model in this work are taken from [18]. In this model a phenomenological approach is developed to account for nucleation, surface growth, coagulation and oxidation of soot particles. Although detailed reaction mechanism for soot formation and oxidation can be found in literature, e.g. [19], accounting for this complex mechanism in the CFD simulation imposes a very high computational cost. However, since the primary importance in the soot production is some pyrolysis products of fuel decomposition, not the fuel itself, the model used in this study is linked to a detailed chemical mechanism for the gas phase reaction which provides a more accurate estimation of soot precursor. Similar to the work of [18], acetylene is chosen as the soot precursor.

The soot formation is initiated by formation of active nuclei from decomposition of soot precursor with a rate constant linearly dependent on the precursor concentration. The second step in the soot mass formation is the surface growth through absorption of acetylene to the surface of the active nuclei. The decrease in the particle number density through agglomeration is modelled using normal square dependence [18]. For soot oxidation, reactions with $\mathrm{O}_{2}$ and $\mathrm{OH}[\underline{20}]$ are considered.

Two transport equations are solved for soot particle number density and soot volume fraction. It is assumed that the oxidation will not affect the soot number density. The above mentioned sub-processes, nucleation, surface growth, coagulation and oxidation, provide the source terms for these two transport equations.

\section{Experimental Conditions and Numerical Cases}

The experimental cases considered in this study are from an open-bowl, heavy duty direct ignition engine. Pressure trace along with the soot and $\mathrm{NO}_{x}$ in the exhaust gas are measured for four different conditions. The main engine parameters are presented in Table 1 . The experiments were performed in two different loads, high load cases, $100 \%$ load, and low load cases, $25 \%$ load. At each load, different amount of fuel was injected resulting in different equivalence ratio in the cylinder.

Six different cases were studied in the numerical simulation. First, all the four cases from the experimental measurements were simulated using 1 RIF. Then two cases, one from each load, was simulated using 12 RIFs to study the effect of increasing the number of flamelet representatives. The details of the parameters in different cases are listed in Table 2.

A $60^{\circ}$ sector of the engine is considered in the simulations. The numerical simulations were started at $235 \mathrm{CAD}$, after the intake valve was closed, with initial pressure and temperature from experimental measurements. The initial gas composition in the engine was estimated from the reported EGR in the experiments. The velocity field was initiated linearly varying from zero in the cylinder head to piston velocity in the bowl. The swirl number was set to zero in this study. $\mathrm{N}$-dodecane was used in the reaction mechanism as the fuel [21]. To have a better representation of the spray characteristics of the diesel surrogate used in the experiments, the liquid properties of a blended fuel, 30\% alpha-methyl-naphthalene with 70\% $\mathrm{n}$-decane, was used for $\mathrm{n}$-dodecane properties.

TABLE 1 Geometry of the studied engine

\begin{tabular}{|l|l}
\hline Nominal compression ratio & $\mathbf{1 5 . 9}$ \\
\hline RPM & 1200 \\
\hline Bore diameter & $131.0 \mathrm{~mm}$ \\
\hline Stroke & $158 \mathrm{~mm}$ \\
\hline Clearance (Nominal) & $1.0 \mathrm{~mm}$ \\
\hline Crevice Width & $0.9 \mathrm{~mm}$ \\
\hline Crevice Length & $11.0 \mathrm{~mm}$ \\
\hline Injection hole size & $212 \mu \mathrm{m}$ \\
\hline Injection pressure & $1500 \mathrm{bar}$ \\
\hline Number of holes & 6 \\
\hline
\end{tabular}


TABLE 2 Details of the operating condition for the simulated cases; SOI: Start of injection, EOI, End of injection, $\lambda_{c y l}$ : In cylinder air to fuel ratio, $\mathrm{CO} 2$ ratio: ratio between in cylinder $\mathrm{CO} 2$ and stoichiometric CO2, HL: High Load, LL: Low Load.

\begin{tabular}{|c|c|c|c|c|}
\hline Load & $100 \%$ & $100 \%$ & $25 \%$ & $25 \%$ \\
\hline SOI (CAD) & 355 & 355 & 357 & 357 \\
\hline EOI (CAD) & 378 & 377 & 363.8 & 363.5 \\
\hline $\begin{array}{l}\text { Mass } \\
\text { injected } \\
(m g)\end{array}$ & 48.86 & 46.67 & 13.17 & 13.19 \\
\hline $\mathrm{CO} 2$ ratio & 0.232 & 0.191 & 0.198 & 0.291 \\
\hline $\begin{array}{l}\text { Intake } \\
\text { temp. (K) }\end{array}$ & 404 & 404 & 390 & 390 \\
\hline$\lambda_{c y l}$ & 1.17 & 1.3 & 1.49 & 1.74 \\
\hline Nr. of RIFs & $1 / 12$ & 1 & 1 & $1 / 12$ \\
\hline \multirow{2}{*}{$\begin{array}{l}\text { Case } \\
\text { reference }\end{array}$} & HL1 & HL2 & LL1 & LL2 \\
\hline & HL1-12RIF & & & LL2-12RIF \\
\hline
\end{tabular}

The mesh was generated using the automatic mesh generation utility provided as a pre-processing tool to Lib-ICE solver [14]. To ensure non-dissipative behaviour in the spray, the mesh was generated in the direction of the spray. Four layers of refinements was used in the radial direction to have a similar resolution throughout the domain. The movement of the mesh was performed using the dynamic mesh layering technique [22], keeping the cells in the spray region fixed and moving the ones in the piston bowl. Figure 1 shows the details of the computational domain and the mesh in this study.

FIGURE 1 Geometry of the engine and the mesh used in the study.

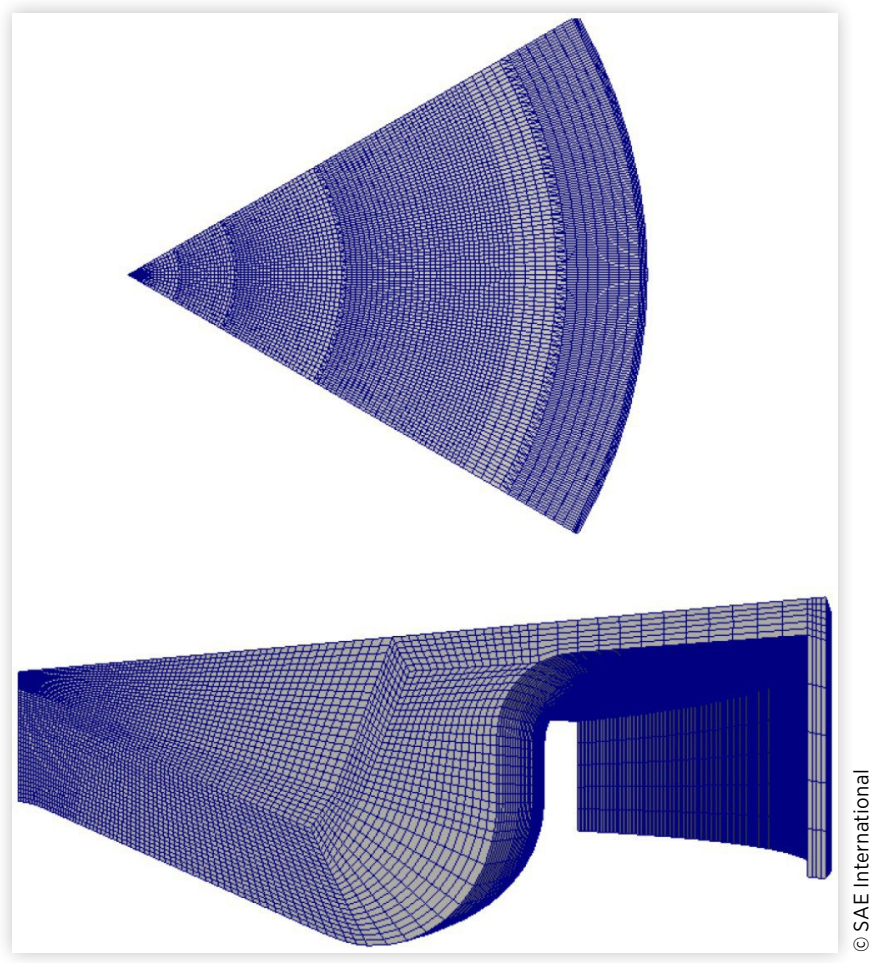

\section{Results and Discussion}

MODEL VALIDATION To validate the model, a comparison between the in-cylinder pressure and the derived heat release rate from the experimental pressure-crank angle data for the four cases studied in the experiments are presented in Figures $2, \underline{3}, \underline{4}$ and $\underline{5}$. For all the cases, the general trends in pressure and heat release rate have been captured by the model very well. For high load cases, Figures 2 and $\underline{3}$, the initial ignition event can be identified from heat release rate rise, and peak of pressure is captured very well. The small deviation on the pressure peak between the model and the experiment, which also shows some effect on the peak of heat release rate comparing with the experiment, can be due to some pockets of unburned fuel due to under-prediction of mixing because of spray model.

For the low load cases, LL1 and LL2 presented in Figures 4 and $\underline{5}$, to have a better comparison to the experiments, the start of injection has been delayed by 1 CAD.

FIGURE 2 In-cylinder pressure for high load cases, HL1 and $\mathrm{HL} 2$. The solid lines are from the experiments and dashed-lines are from the numerical simulations
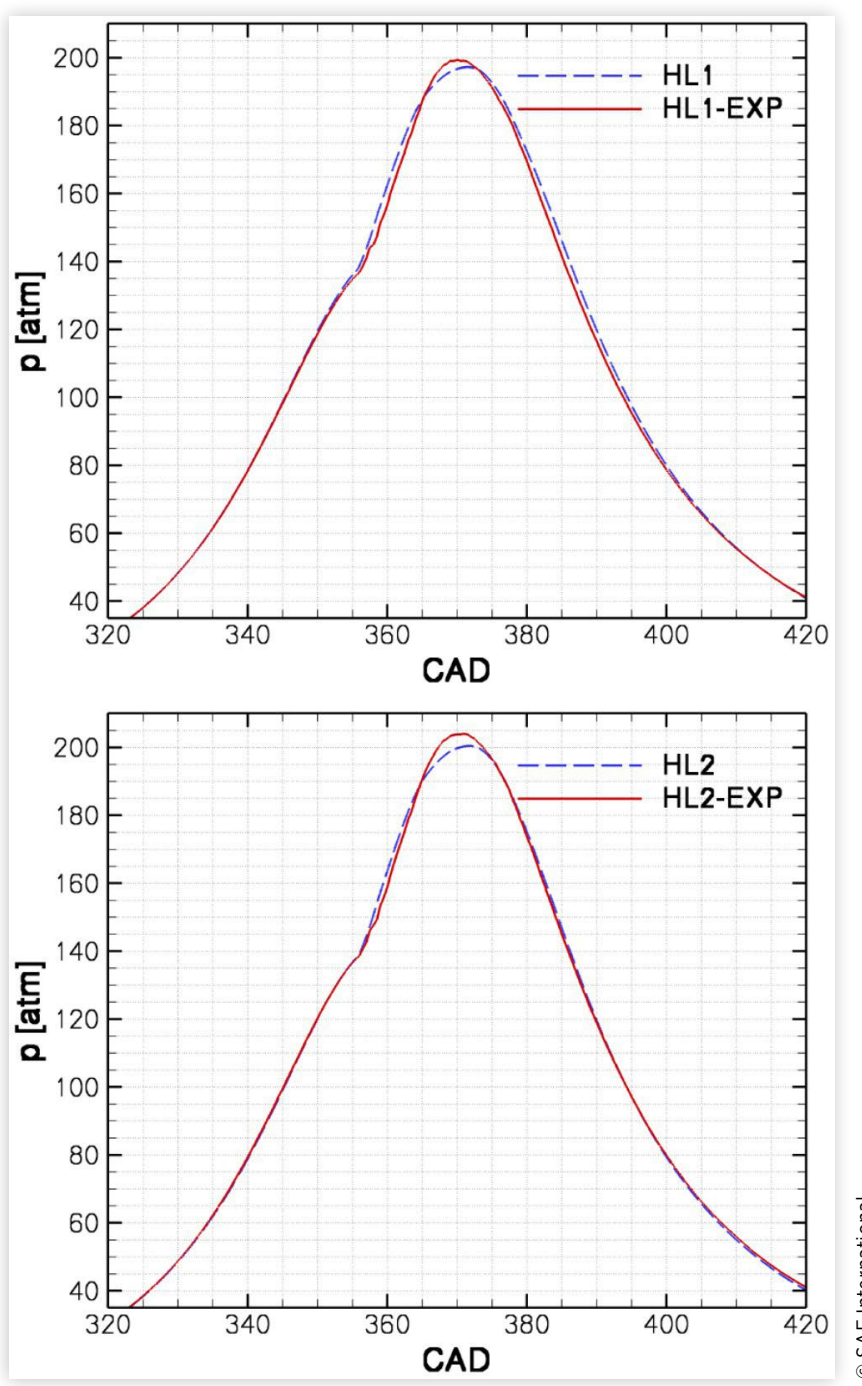
FIGURE 3 Apparent heat release rate for high load cases, $\mathrm{HL} 1$ and HL2. The solid lines are from the experiments and dashed-lines are from the numerical simulations

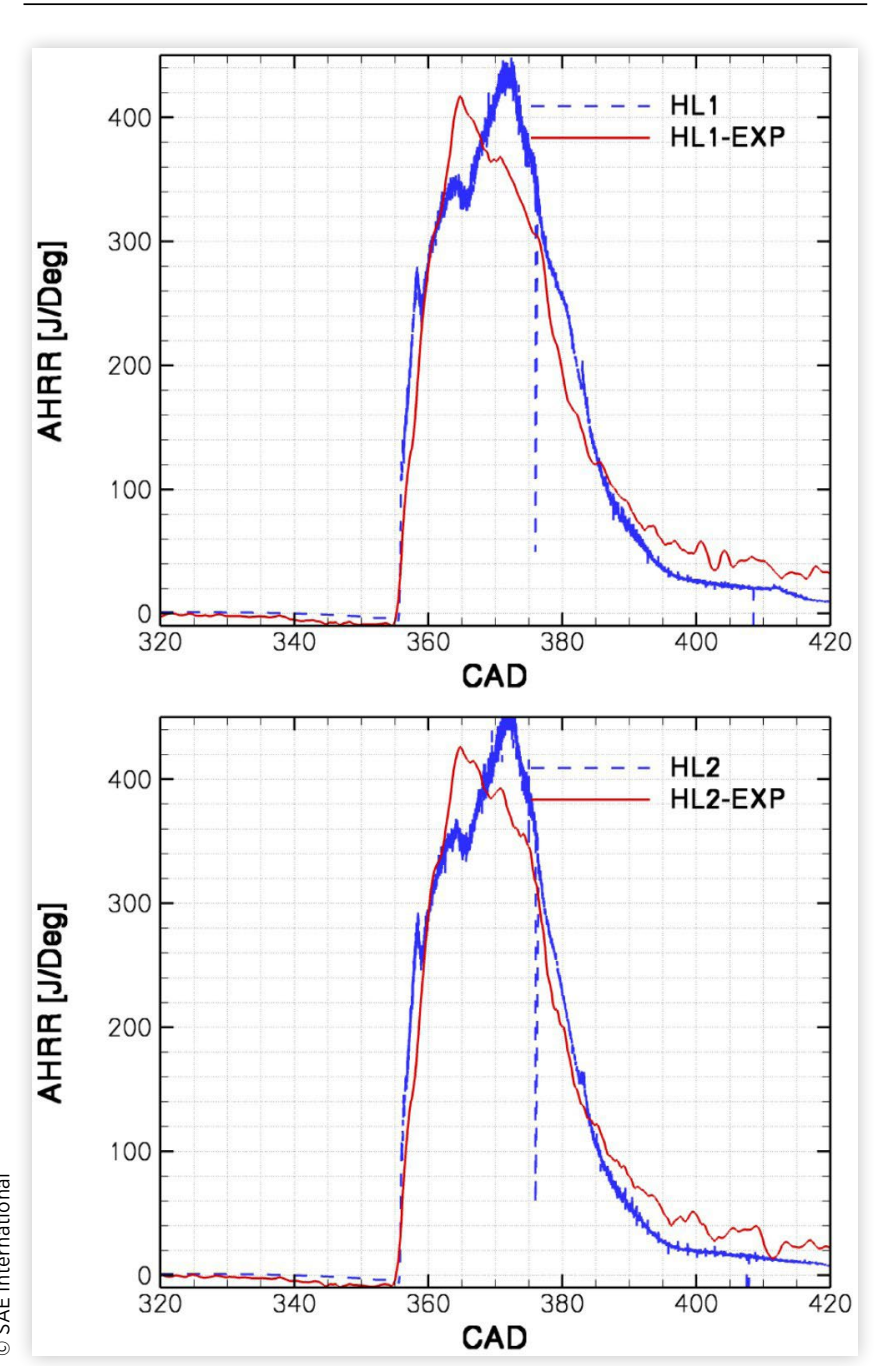

By this small adjustment, the initial ignition event shows a perfect match to the measured data. On the other hand, the peak pressure has been under-predicted. In the low load cases, presence of premixed combustion is more dominant compared to the high load cases. The sharp pressure rise in LL1 and LL2 due to the rapid premixed combustion phase is captured by the model, but to a less extent compared to the experiments. The deviation can be identified more clearly in comparing the heat release rates, as an indication of pressure gradient. While the model shows a peak in heat release rate right after the start of main ignition event, this phase dies out much faster compared to the experiment. On the other hand, the peak value for the heat release rate is much higher, $1200 \mathrm{~J} / \mathrm{deg}$ in LL1 and $1000 \mathrm{~J} / \mathrm{deg}$ in LL2 compared with $400 \mathrm{~J} / \mathrm{deg}$ in the experiment. This deviation can be due to two factors, first that the mixing between the air and fuel is under-predicted or that the kinetic mechanism predicts a much faster reaction rate for the premixed mixture. One should also bear in mind that the experimental data are from cycle to cycle averaging.
FIGURE 4 In-cylinder pressure for low load cases, LL1 and LL2. The solid lines are from the experiments and dashed-lines are from the numerical simulations

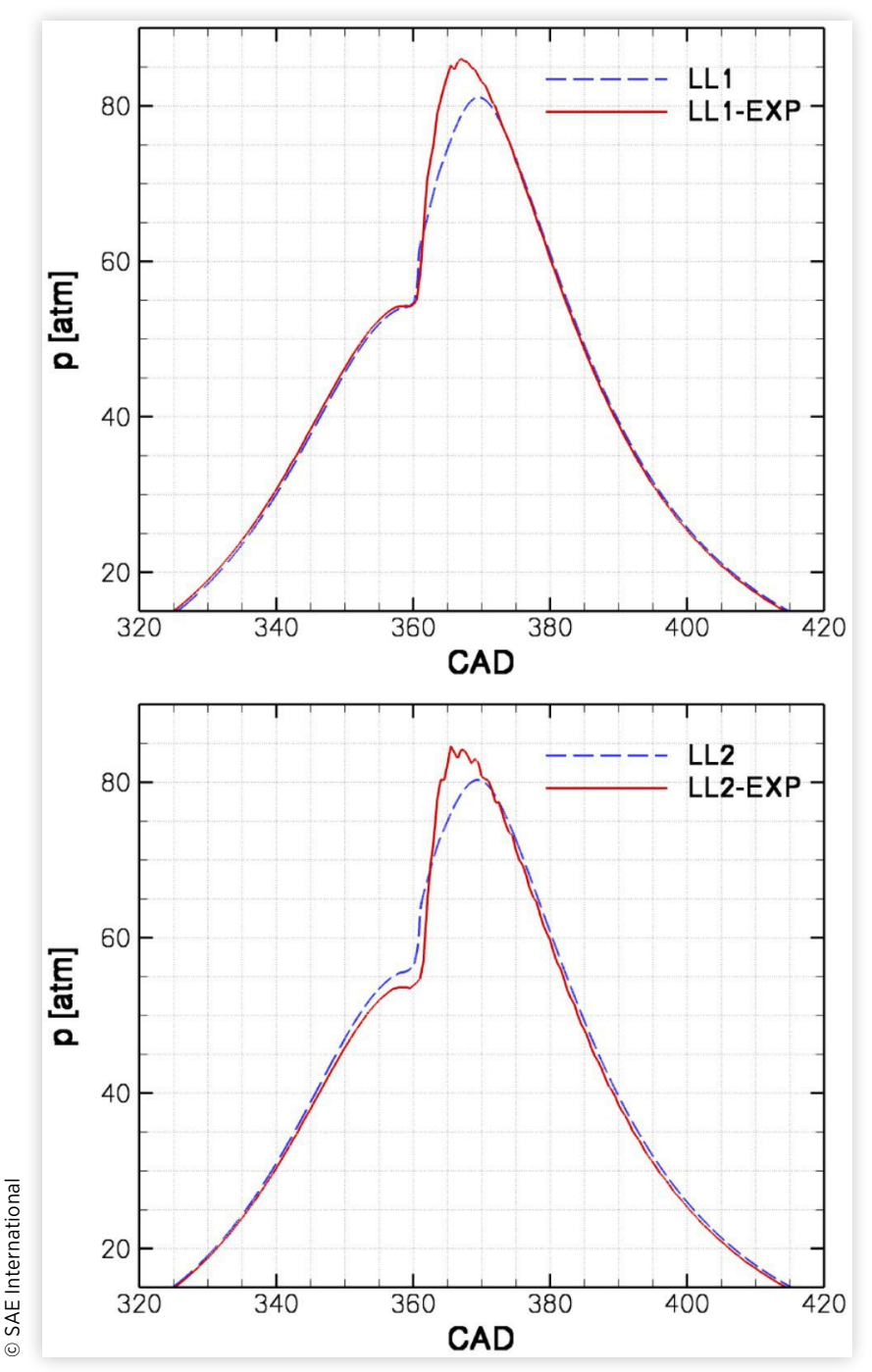

The temperature field before and after the main ignition event for LL2 cases is presented in Figure 6. The color map of the contours are kept at a constant range, between 400 to $2000 \mathrm{~K}$, to provide a better comparison between different times. The line represent the stoichiometric mixture fraction and the Lagrangian droplets are also included in the figure. Shortly after the SOI, at $385.5 \mathrm{CAD}$, a pool of $\mathrm{H}_{2} \mathrm{O}_{2}$ and $\mathrm{HO}_{2}$ appears around the spray, covering the lean and rich regions. This is an indication of low temperature reaction before the main ignition event. As a result, the temperature at 2.5 CAD after SOI rises to $1300 \mathrm{~K}$ from $900 \mathrm{~K}$ at SOI. The main ignition event can be identified in this figure at $3 \mathrm{CAD}$ after SOI followed by a sudden rise in the temperature. The following sequence shows a diffusion flame around the jet.

SOOT A comparison between the numerical simulations for soot and the measured soot values at the exhaust of the engine, dimension in $\mathrm{g} / \mathrm{kWh}$, is presented in Figure 7. Despite the fact that the absolute values from the model show large 
FIGURE 5 Apparent heat release rate for low load cases, LL1 and LL2. The solid lines are from the experiments and dashed-lines are from the numerical simulations

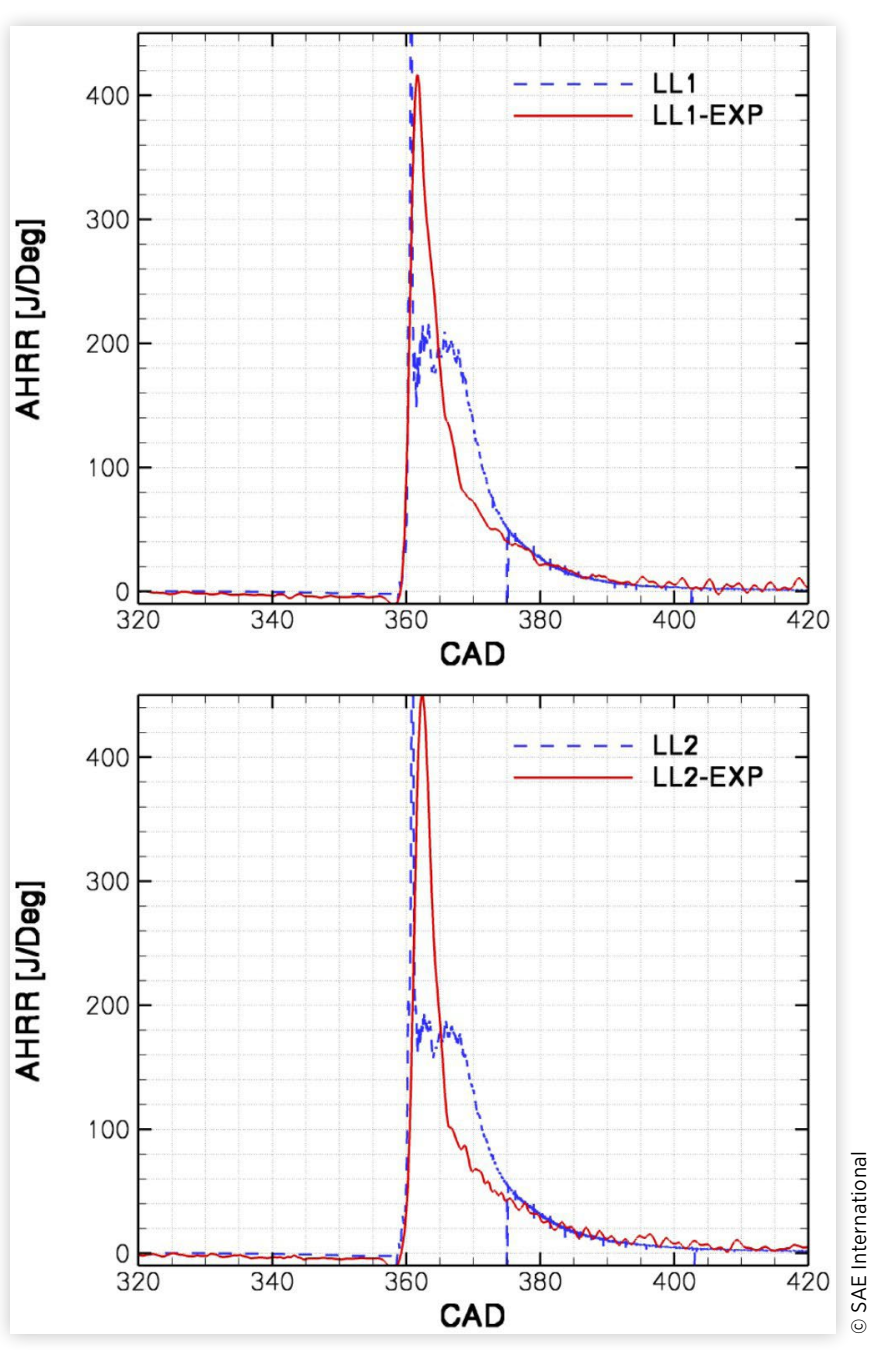

deviation comparing to the experimental data, the trend between the four cases is correctly captured by the model. One reason for higher values of soot in the model for high load cases can be due to the fact that the data for the total soot mass are extracted at $480 \mathrm{CAD}$ in the model. The profile of the total in-cylinder soot mass, presented in Figure 8, shows that the soot mass is still decreasing with a noticeable gradient.

Another observation from Figure 8 is the effect of higher number of RIFs on the behaviour of the soot model. By increasing the number of RIfs, the model predicts higher mass of soot inside the cylinder. The effect is only noticeable for the high load case, since for the low load case the duration of the injection is very short and the effect of using higher number of RIFs is insignificant. Increasing the number of RIFs has minor effect on the global parameters such as cylinder pressure and temperature, however, locally, the model produce different flame structure. A higher average of scalar dissipation rate can be obtained by increasing the number of RIFs and at the same time more variation in the mixture fraction is considered in the model.
Mean scalar dissipation rate in the $\mathrm{T}-\mathrm{Z}$ coordinates for all the discrete points in the CFD domain for HL1 cases with 1 and 12 RIFs is plotted in Figure 9. As evident from this figure, by increasing the number of RIFs, the mean value of scalar dissipation rate become considerably higher, note the difference in the color map. Previous studies has shown that the nucleation rate of soot is highly sensitive to the strain rates in the flow [23]. Higher values of scalar dissipation rate in the presence of larger spread in the mixture fraction result in the higher soot formation. In other word, larger fraction of the domain is in fuel rich region which is in favour of soot formation. Comparing the scatter plot between the two cases, Figure 9a, the only noticeable difference is that by adding more number of RIFs a tail of higher values of mixture fraction appears. In Figure 9b, the count or PDF of the temperature and mixture fraction is presented. The data presented in this figure shows in how many cells (in a log scale) in the CFD domain an specific combination of $\mathrm{T}$ and $\mathrm{Z}$ exist. From this data, the mixture fraction tail in HL1-12RIF case covers only a limited number cells in the CFD domain compared to the region of stoichiometric mixture fraction. Despite the fact that small parts of the domain have very rich mixture, the effect on the soot formation is significant.

The mass of soot presented in Figure 8 is the result of different sub-processes, nucleation (formation), surface growth, coagulation and oxidation, as explained in the previous section. For three time instances after the start of injection, the soot volume fraction, soot formation and soot oxidation rates are presented in Figure 10. The time instances represent the steady phase of the injection at $363 \mathrm{CAD}$, close to the end of injection at $378 \mathrm{CAD}$ and after the end of injection at $393 \mathrm{CAD}$. In the early phase of soot formation, e.g. at $363 \mathrm{CAD}$, the region of high soot volume fraction corresponds to the region of soot formation. The soot formation region is covered by a thin layer of soot oxidation which is the region of high temperature with the presence of excess oxygen. Towards the end of the injection, however, the higher values of soot volume fraction do not correspond with the soot formation region. The soot is transported towards the center of the engine where the temperature is relatively lower and despite the high concentration of $\mathrm{O}_{2}$, the soot oxidation is insignificant in this region. At $393 \mathrm{CAD}$, the formation of soot is practically zero and the soot oxidation has a lower rate compared to the earlier time in the process. The high amount of soot in this case is due to the low mixing in the engine.

The vorticity field and velocity vectors at several crank angle degrees at a cut plane in the middle of injection plane are presented in Figure 11. Two planes are presented next to each others to better present the flow structure between the sprays. The red color in the contours represents region of counter-clockwise motion and the blue color in the contours represents the region of clockwise motion. When the spray hit the cylinder wall, two counter rotating vortexes are formed between the sprays. The vortexes grow towards the cylinder center at later crank angels and start to mix together after the end of injection. Right at the border between the high vorticity regions (red and blue colors) with no vorticity regions (green 
FIGURE 6 2D contour of temperature in a mid-injector plan for time instances between 0.5 to 10 CAD after the start of injection. The solid line represent the stoichiometric mixture fraction.

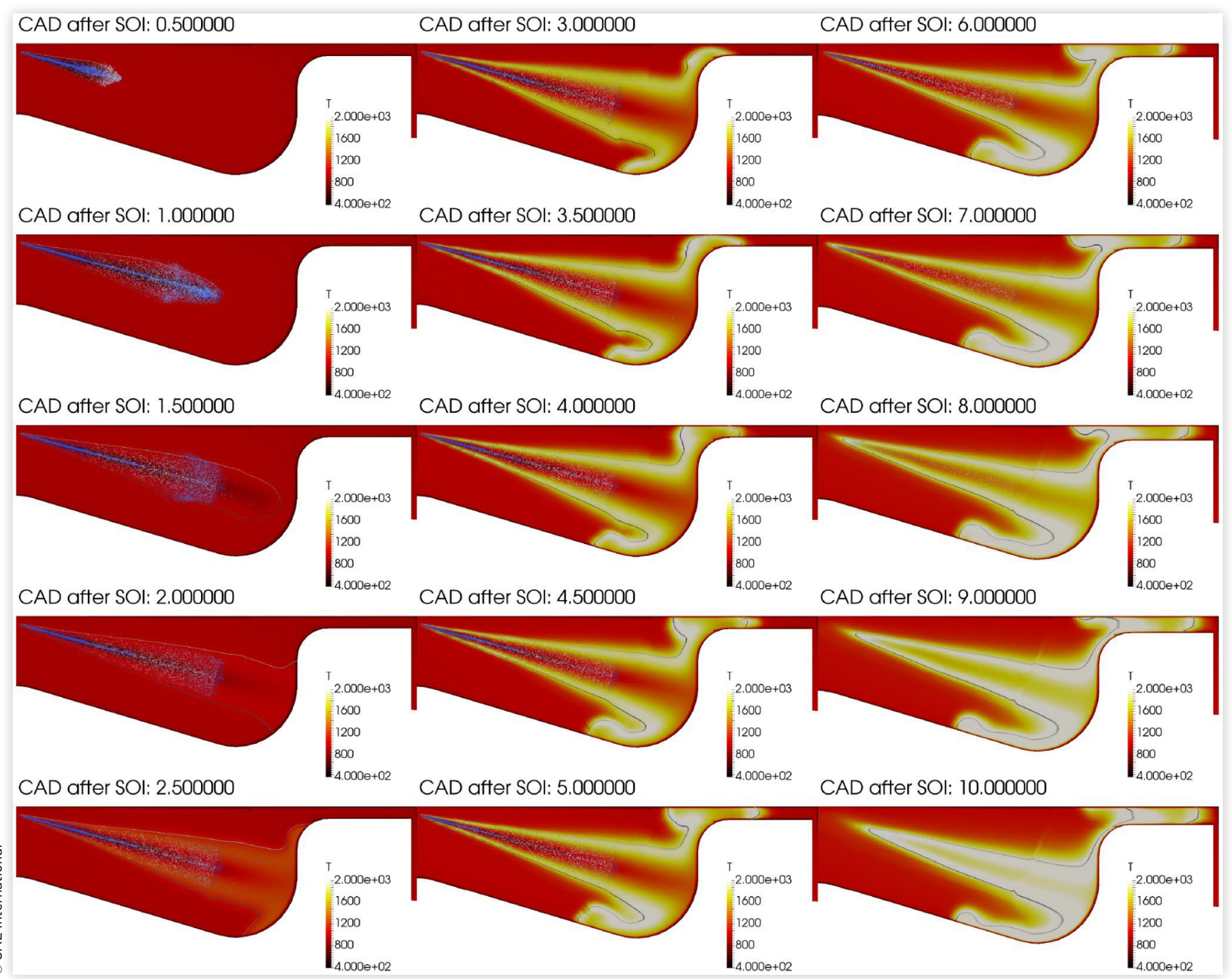

FIGURE $7 \mathrm{~g} / \mathrm{kWh}$ of soot at the exhaust of the engine. Comparison between the model and the experiment.

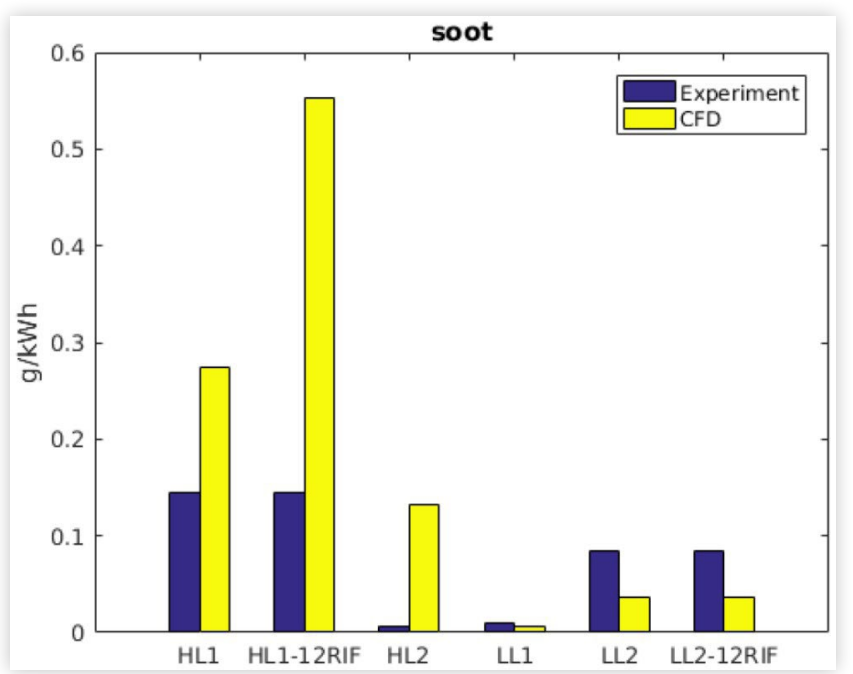

color) a small region of vorticity with opposite sign exists. Comparing with the velocity vectors which are superimposed on top of the vorticity contours, these small regions are local flow rotations while the large vorticity regions are coherent flow structures. These coherent flow structures, forming symmetrically at both sides of the spray, are the main mechanism for entrainment of air to fuel rich regions.

To further investigate the effect of large scale structures on the mixing and to elucidate the physical processes that lead to soot oxidation in these engine configuration, new variables, velocity times the gradient of $\mathrm{O}_{2}$ and $\mathrm{OH}$, is employed, following the work of [24].

$$
\alpha_{\mathrm{O} 2}=u \cdot \nabla Y_{\mathrm{O} 2} \text { and } \alpha_{\mathrm{OH}}=u \cdot \nabla Y_{\mathrm{OH}}
$$

These fields represent the relative motion of the flow field to the oxidisers concentration. The positive values of these fields represent the depletion of oxidisers towards the higher concentrations and the negative values represents the mixing of oxidisers into the fuel rich regions. 
FIGURE 8 Total mass of soot in cylinder for the six numerical cases.

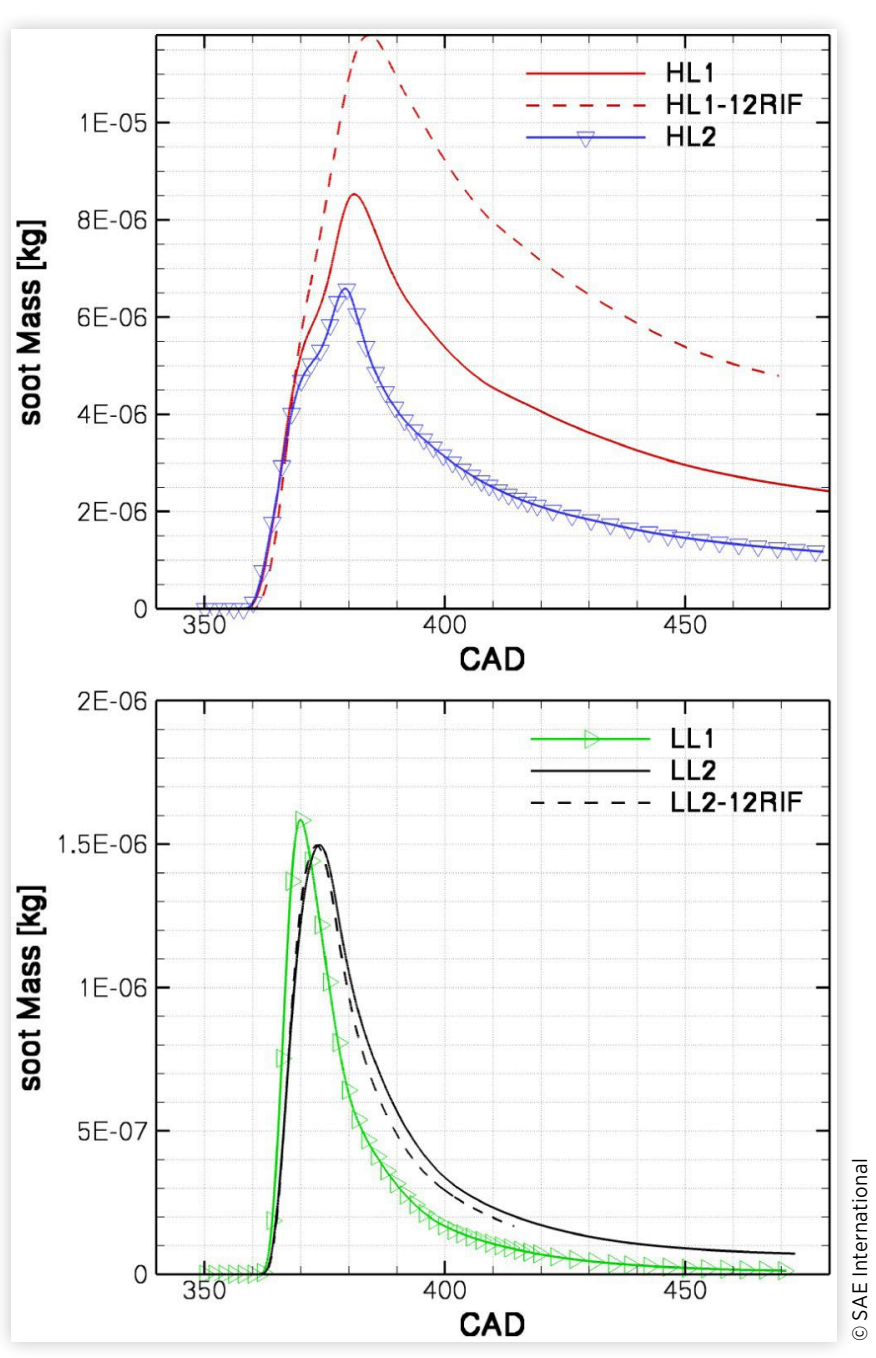

In Figure 12 the effects of large scale mixing on the amount of soot in the cylinder and also on the soot oxidation are presented. On the left column, the contours show the $\alpha_{O 2}$ field and the lines show the mass of soot in the cylinder. On the right column, the contours show the $\alpha_{O H}$ field and the lines show the soot oxidation rate. The red color shows the positive values of $\alpha_{\mathrm{O} 2}$ and $\alpha_{\mathrm{OH}}$ which shows the oxidiser depletion regions and the blue color shows the negative values of the two fields representing feeding of oxidisers to those regions.

The first appearance of soot in the cut plane in the middle of the injection plane occurs at 360 CAD in the region of positive $\alpha_{\mathrm{O} 2}$ close to the wall. While the oxidation of fuel leaves no oxygen for soot oxidation in this region, the presence of $\mathrm{OH}$ contributes to the soot oxidation from the early stage of soot formation, as seen from the first figure in the right column. At the later crank angles, the soot mass is transported towards the cylinder center while the soot oxidation closely follows the negative regions of $\alpha_{\mathrm{O} 2}$ and $\alpha_{\mathrm{OH}}$ fields. By comparing Figures 11 and $\underline{12}$ one can see that the regions of soot oxidation are at the edge of the coherent flow structures while the soot mass mainly exists in the body of these structure.

$\mathrm{NO}_{X}$ Figure 13 shows comparison of the $\mathrm{NO}_{x}$ at the exhaust of the engine between the experiments and the model predictions. Results from different strategies for modelling $\mathrm{NO}_{x}$, as explained in the previous section, is shown in this figure. The agreement between the model results and the measurements are only qualitative. The model systematically under-predicts the $\mathrm{NO}_{x}$ formation in this set-up. One explanation for this can be the global amount of residuals estimated from external gas recirculation and gas exchange process. The amount of residual gases is probably overestimated which has led to under-prediction of $\mathrm{NO}_{x}$ in the simulations.

Different modelling strategies shows considerable effect on the calculated $\mathrm{NO}_{x}$. By directly integrating $\mathrm{NO}_{x}$ from flamelet library, much higher value of $\mathrm{NO}_{x}$ is predicted. While by solving the transport equations for $\mathrm{NO}$ in the CFD domain with source term directly calculated in CFD domain or extracted from flamelet library lower values of $\mathrm{NO}_{x}$ is predicted.

For the HL2 case, the mass fraction of NO at 363 CAD calculated from different modelling strategies is plotted as a function of temperature in Figure 14. As expected, the NO from RIF spreads over a narrower region, since the effect of temperature stratification is not included in the model. By solving the transport equations for $\mathrm{NO}$ in the CFD domain, this effect is accounted for and NO exists in lower concentration, but with a wider range.

\section{Conclusion}

Multiple Representative Interactive Flamelet approach was used in this work to study soot and $\mathrm{NO}_{x}$ formation in a heavy duty engine under low load and high load. Four experimental cases were considered in two different loads with different amount of injected fuel at different SOI. The numerical results using 1 and 12 RIFs were presented and compared with the experimental measurements. The comparison between the pressure trace and heat release rate for all the four cases was shown to be in fairly good agreement. The model showed a decrease in the gradient of pressure for low load cases, deviating from the experiments. However, the start of the main ignition event was captured with a very good margin. The soot model was able to correctly predict the trends between the four cases. By using more RIFs in the model, higher amount of soot was predicted. The effect of using more RIFs on the model was discussed. It was shown that the model can capture the variation in the mixture fraction and it's effect on the soot formation very well. In the HL1-12RIF case, by increasing the number of RIFs compared with HL1 case, the PDF of T-Z distribution showed that only a small part of the CFD domain was in the high mixture fraction region, however, the effect of this shift on the soot formation was significant. For $\mathrm{NO}_{x}$, three different modelling strategies were used. The mass fraction $\mathrm{NO}_{x}$ when directly extracted from flamelet library showed higher values compared with the values when transport equation for $\mathrm{NO}_{x}$ is solved in the CFD domain. 
FIGURE 9 (a) Scatter plot of scalar dissipation rate in T-Z coordinate for HL1 cases, comparison between 1 and 12 RIFs, (b) Number of cells in the CFD domain for each T-Z point
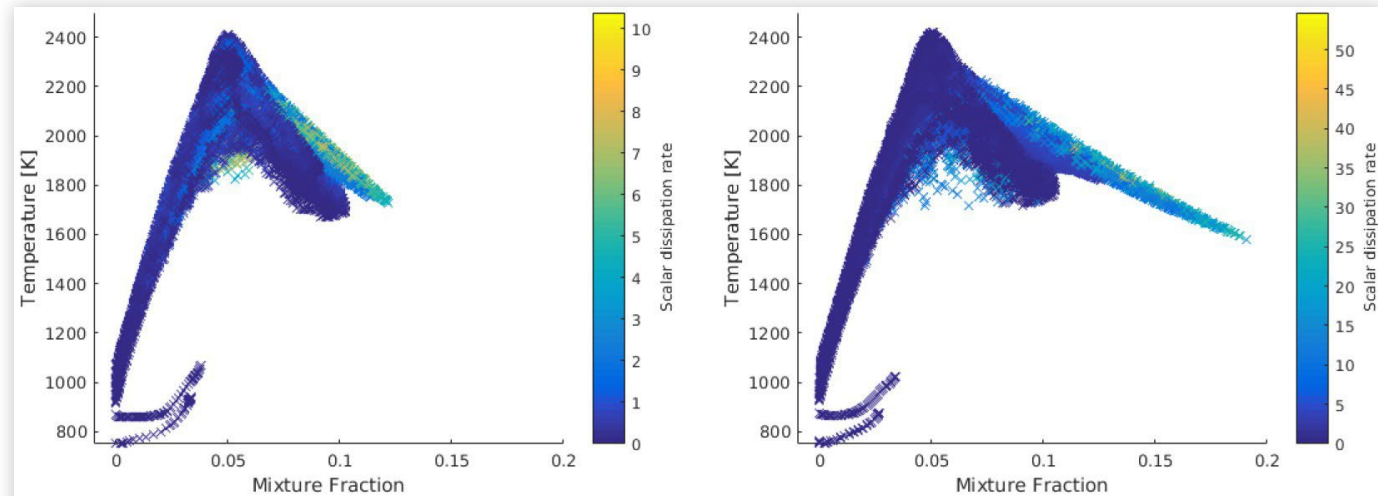

(a)
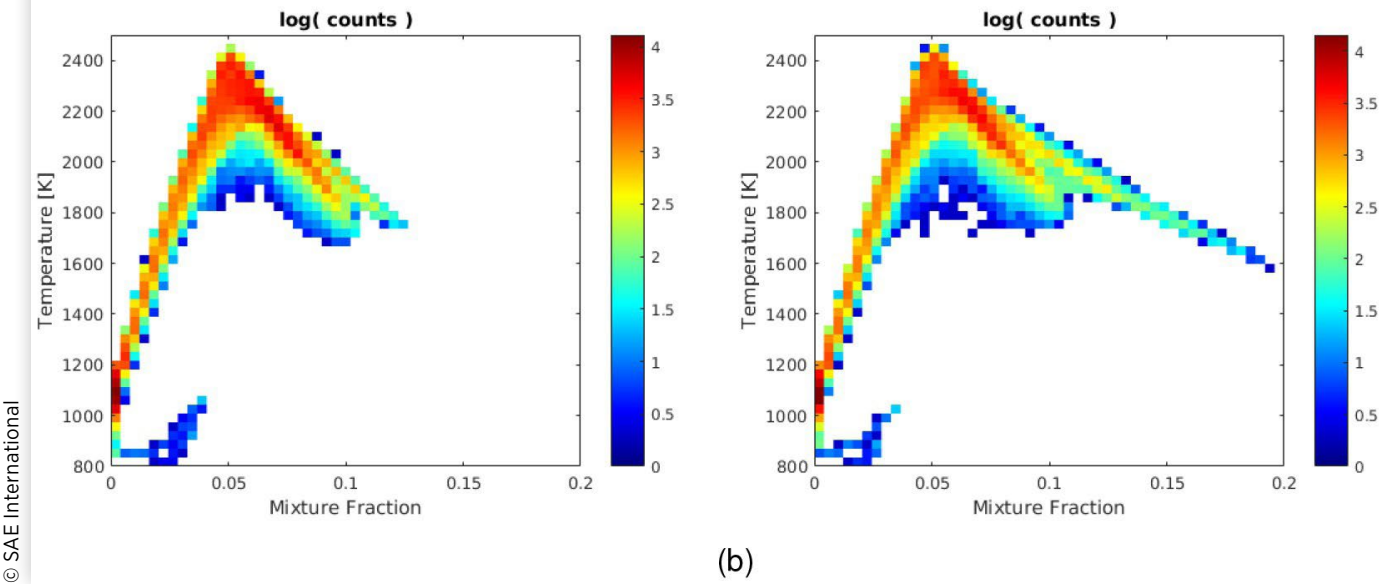

(b)

\section{FIGURE 10 Soot volume fraction, soot formation and soot oxidation at 3 different time instances.}

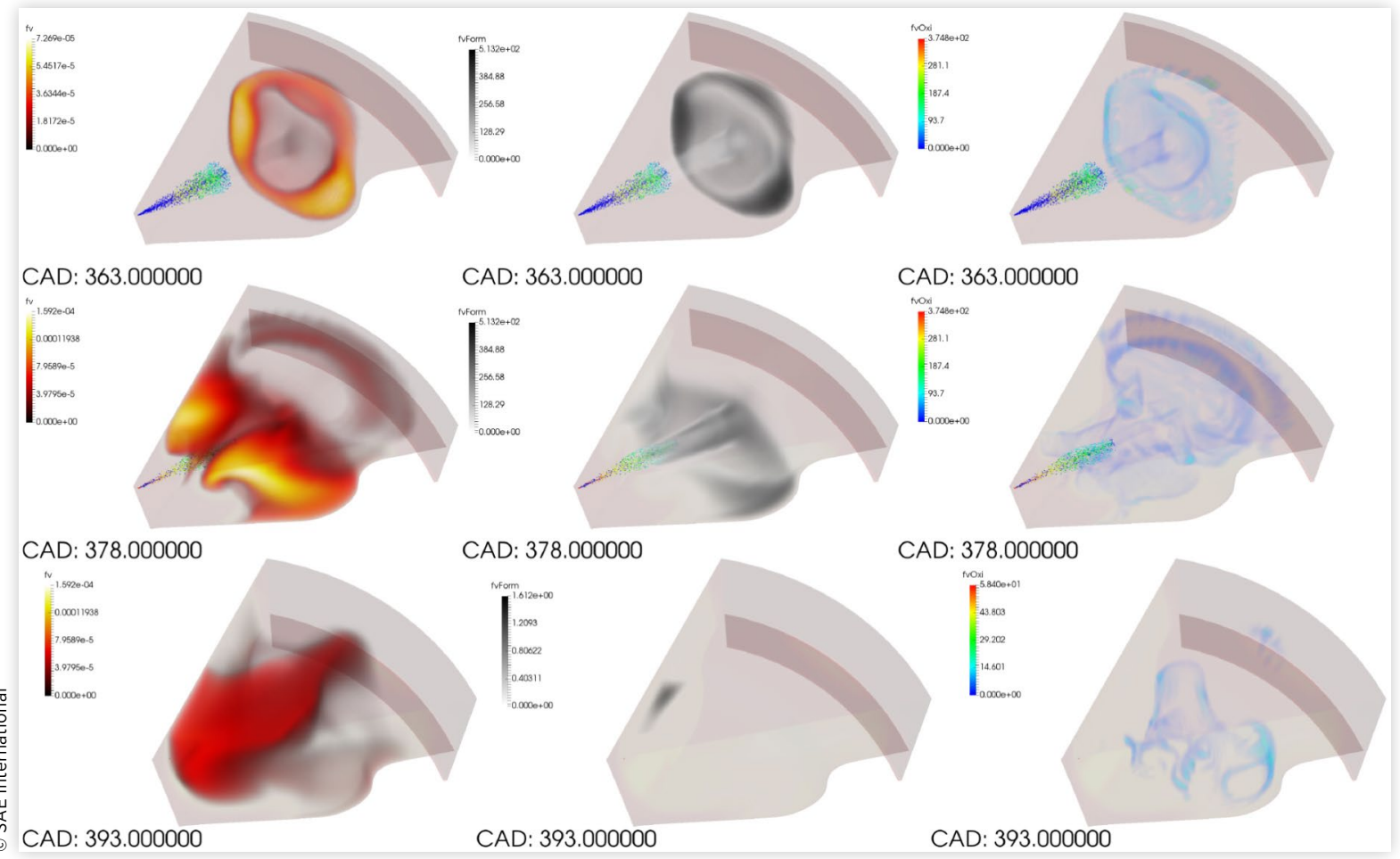


FIGURE 11 Vorticity fields and velocity vectors in a cut plane in the middle of injection plane (angle $150 \mathrm{deg}$ ) at several CAD, case HL1.

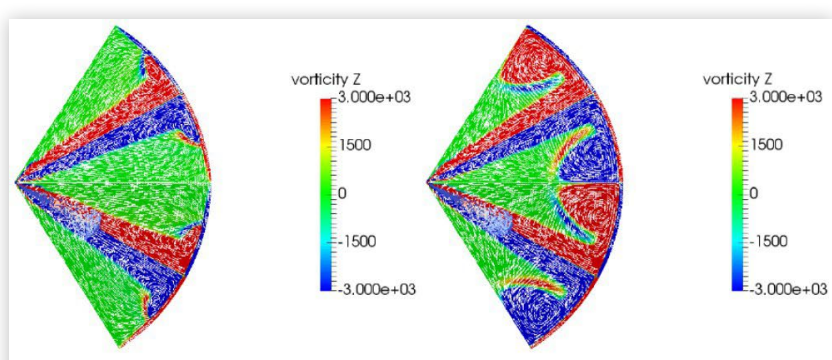

CAD: 360.000000

(a)

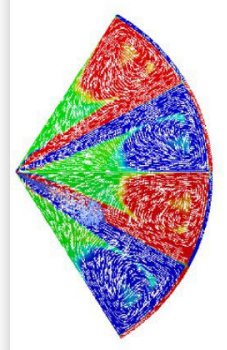

CAD: 372.000000

(c)

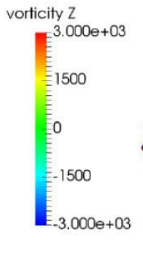

CAD: 368.000000

(b)

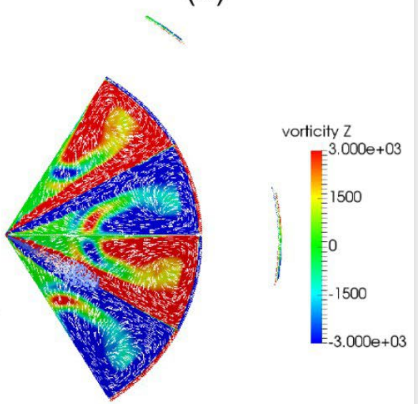

CAD: 376.000000

(d)

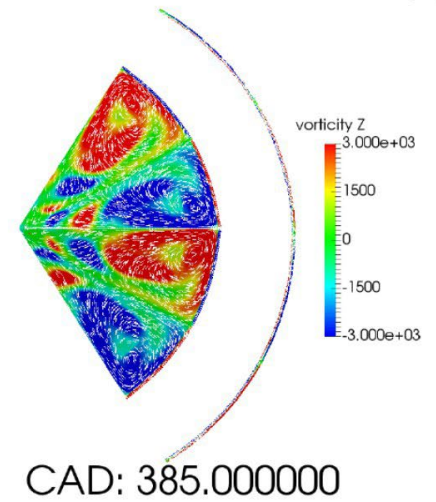

(e) 
FIGURE 12 Effect of large scale mixing on the soot and soot oxidation at several CAD, case HL1.

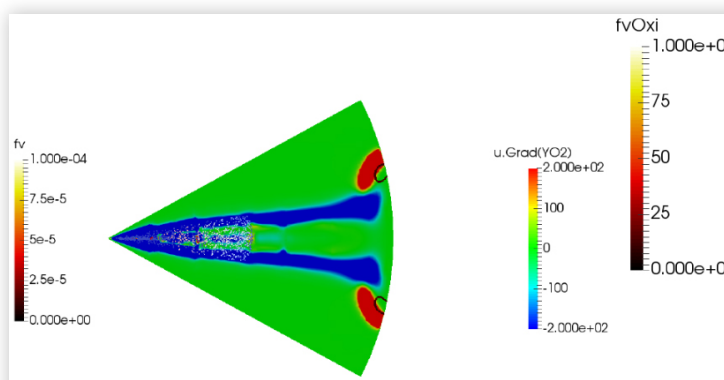

CAD: 360.000000

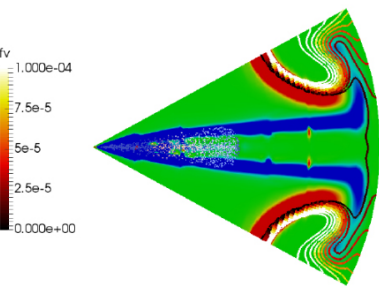

CAD: 368.000000

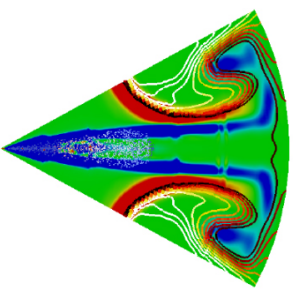

CAD: 372.000000

Wome.s

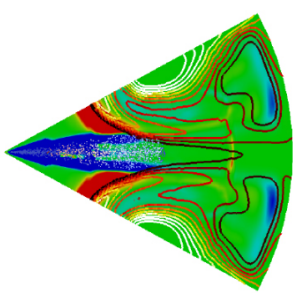

CAD: 376.000000

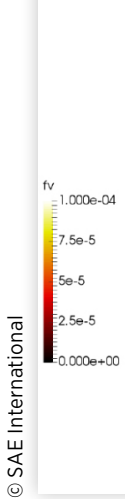

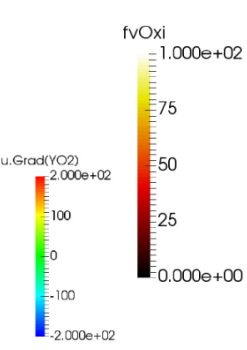

CAD: 360.000000

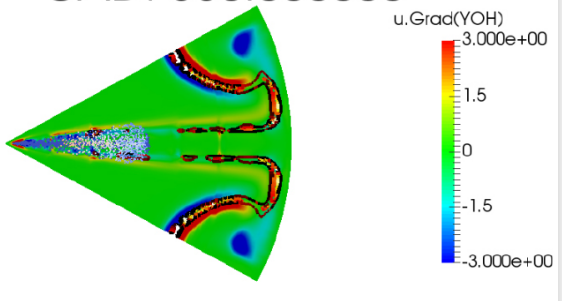

CAD: 368.000000
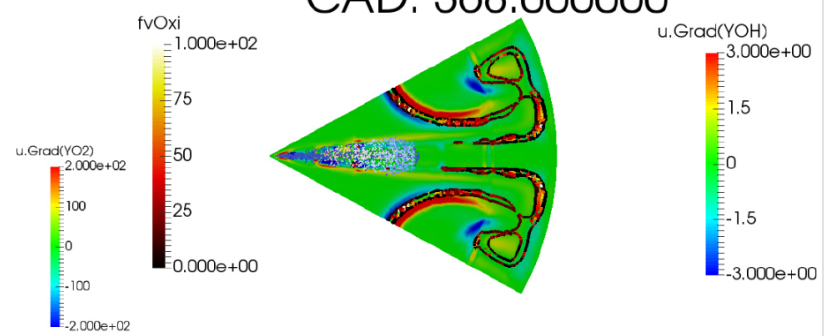

CAD: 372.000000
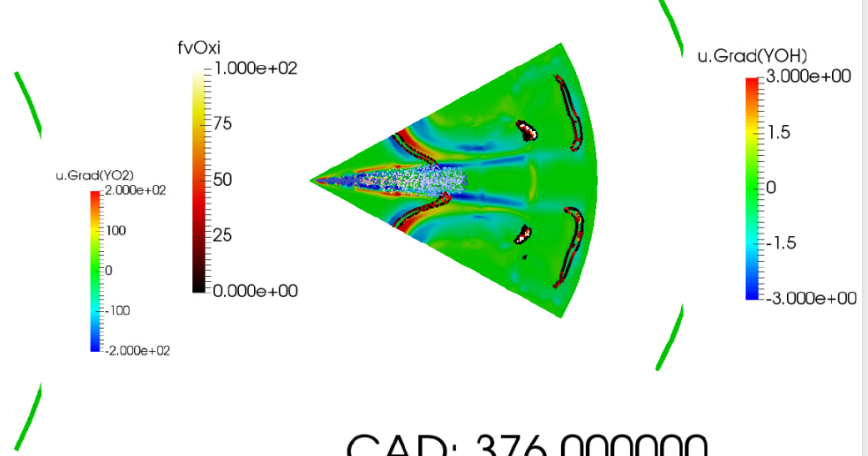

CAD: 376.000000
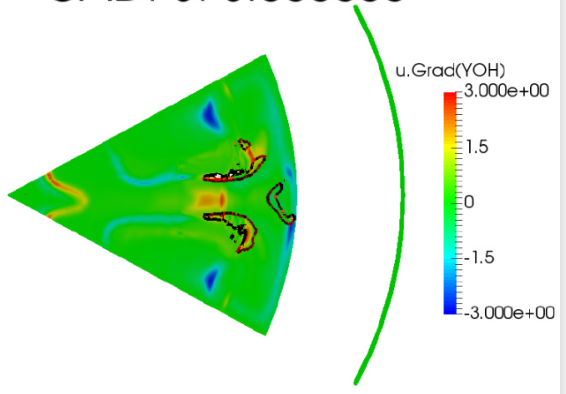

CAD: 385.000000 
FIGURE $13 \mathrm{~g} / \mathrm{kWh}$ of $\mathrm{NO}_{x}$ at the exhaust of the engine. Comparison between the model and the experiment.

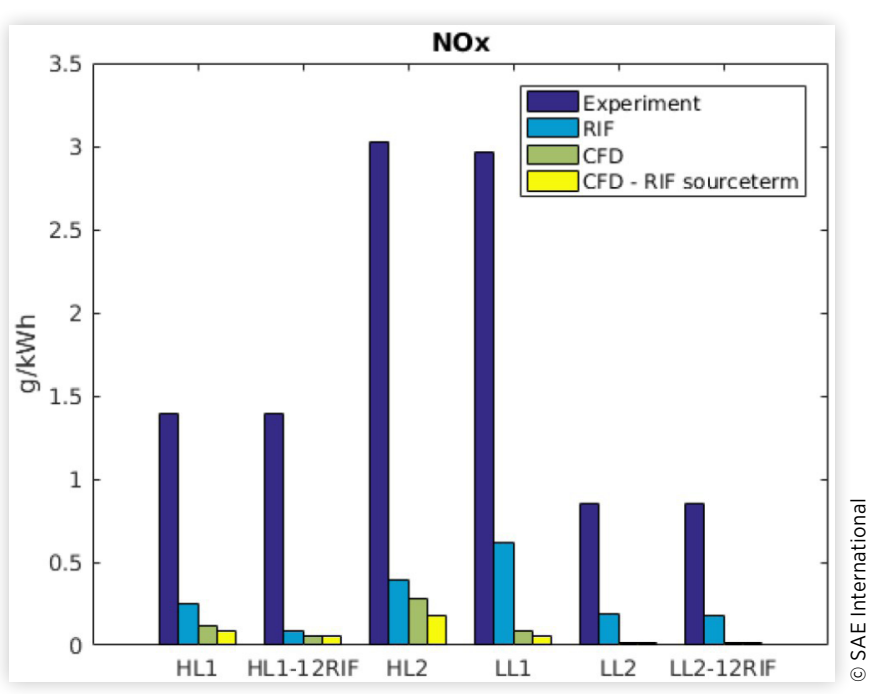

FIGURE 14 Mass fraction of NO vs temperature at 363 CAD for HL2 case; Behaviour of different modelling strategies on the NO formation.

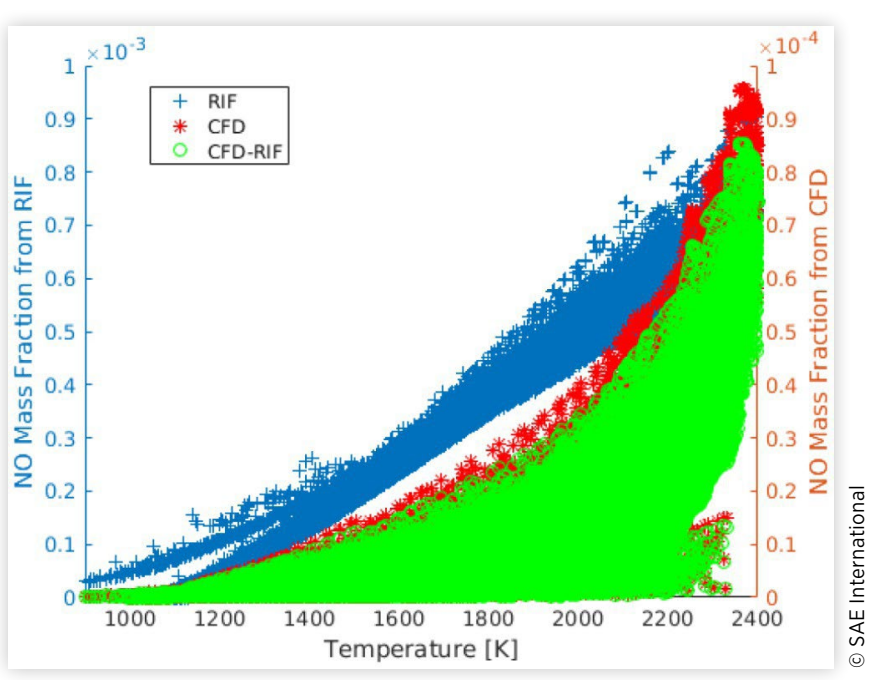

\section{References}

1. Lu, T. and Law, C.K., "Toward Accommodating Realistic Fuel Chemistry in Large-Scale Computations," Progress in Energy and Combustion Science, 350(2): 192-215, 2009. ISSN 0360-1285, doi: https://doi.org/10.1016/j.pecs.2008.10.002. URL http://www.sciencedirect.com/science/article/pii/ S036012850800066X.

2. Contino, F., Jeanmart, H., Lucchini, T., and D'Errico, G., "Coupling of In Situ Adaptive Tabulation and Dynamic Adaptive Chemistry: An Effective Method for Solving Combustion in Engine Simulations. Proceedings of the Combustion Institute, 330 (2):3057-3064, 2011. ISSN 15407489, doi:10.1016/j.proci.2010.08.002. URL http://www. sciencedirect.com/science/article/pii/S1540748910003627.
3. Peters, N., "Local Quenching Due to Flame Stretch and NonPremixed Turbulent," Combustion Science and Technology, 300(1-6):1-17, 1983, doi:10.1080/00102208308923608, URL doi:10.1080/00102208308923608, 30, 1, 17.

4. Peters, N., "Laminar Diffusion Flamelet Models in NonPremixed Turbulent Combustion," Progress in Energy and Combustion Science, 100(3):319-339, 1984. ISSN 0360-1285, doi:10.1016/0360-1285(84)90114-X, URL http://www. sciencedirect.com/science/article/pii/036012858490114X.

5. Pitsch, H., Barths, H., and Peters, N., “Three-Dimensional Modeling of Nox and Soot Formation in di-Diesel Engines Using Detailed Chemistry Based on the Interactive Flamelet Approach," In 1996 SAE International Fall Fuels and Lubricants Meeting and Exhibition, SAE International, Oct 1996, doi:10.4271/962057. URL doi:10.4271/962057.

6. Gopalakrishnan, V. and Abraham, J., "An Investigation of Ignition and Heat Release Characteristics in a Diesel Engine Using an Interactive Flamelet Model," In SAE 2003 World Congress \& Exhibition, SAE International, Mar 2003, doi:10.4271/2003-01-1062. URL https://doi. org/10.4271/2003-01-1062.

7. Wan, Y. P., Pitsch, H., and Peters, N., "Simulation of Autoignition Delay and Location of Fuel Sprays Under Diesel-Engine Relevant Conditions," In International Spring Fuels \& Lubricants Meeting \& Exposition, SAE International, May 1997, doi:10.4271/971590. URL $\underline{\text { https://doi. }}$ org/10.4271/971590.

8. Hergart, C., Barths, H., and Peters, N., "Modeling the Combustion in a Small-Bore Diesel Engine Using a Method Based on Representative Interactive Flamelets," In International Fuels \& Lubricants Meeting \& Exposition, SAE International, Oct 1999, doi:10.4271/1999-01-3550, URL https://doi.org/10.4271/1999-01-3550.

9. Barths, H., Hasse, C., and Peters, N., "Computational Fluid Dynamics Modelling of Non-Premixed Combustion in Direct Injection Diesel Engines," International Journal of Engine Research 10(3):249-267, 2000, doi:10.1243/1468087001545164 URL https://doi. org/10.1243/146808700154516.

10. Lehtiniemi, H., Zhang, Y., Rawat, R., and Mauss, F., "Efficient 3-d cfd Combustion Modeling with Transient Flamelet Models," SAE Technical Paper 2008-01-0957, 04 2008, doi:10.4271/2008-01-0957, URL https://doi. org/10.4271/2008-01-0957.

11. D’Errico, G., Lucchini, T., Hardy, G., Tap, F. et al., "Combustion Modeling in Heavy Duty Diesel Engines Using Detailed Chemistry and Turbulence-Chemistry Interaction," SAE Technical Paper 2015-01-0375, 04 2015, doi:10.4271/2015-01-0375, URL https://doi. org/10.4271/2015-01-0375.

12. Lucchini, T., D’Errico, G., Onorati, A., Bonandrini, G. et al., "Development of a cfd Approach to Model Fuel-Air Mixing in Gasoline Direct-Injection Engines," In SAE 2012 World Congress \& Exhibition, SAE International, Apr 2012, doi:10.4271/2012-01-0146, URL https://doi. org/10.4271/2012-01-0146.

13. D’Errico, G., Lucchini, T.Di Gioia, R., and ,Bonandrini, G., "Application of the ctc Model to Predict Combustion and Pollutant Emissions in a Common-Rail Diesel Engine Operating with Multiple Injections and High egr," In $S A E$ 
2012 World Congress \& Exhibition," SAE International, Apr 2012, doi:10.4271/2012-01-0154. URL https://doi. org/10.4271/2012-01-0154.

14. Lucchini, T., Fiocco, M., Torelli, R., and D'Errico, G., "Automatic Mech Generation for Full-Cycle cfd Modeling of ic Engines: Application to the tcc Test Case. In SAE 2014 World Congress \& Exhibition. SAE International, Apr 2014, doi:10.4271/2014-01-1131. URL https://doi.org/10.4271/201401-1131.

15. Reitz, R. et al., "Modeling Atomization Processes in HighPressure Vaporizing Sprays," Atomisation and Spray Technology 30(4):309-337, 1987.

16. Chehroudi, B., Chen, S-H., Bracco, F.V., and Onuma, Y., "On the Intact Core of Full-cone Sprays," SAE Technical Paper 850126, 02 1985, doi:10.4271/850126. URL https://doi. org/10.4271/850126.

17. Felsch, C., Gauding, M., Vanegas, A., Won, H. et al., "Evaluation of Modeling Approaches for Nox Formation in a Common-Rail Di Diesel Engine Within the Framework of Representative Interactive Flamelets (rif), " In SAE World Congress (ઐ) Exhibition, SAE International, Apr 2008, doi:10.4271/2008-01-0971. URL https://doi. org/10.4271/2008-01-0971.

18. Leung, K.M., Lindstedt, R.P., and Jones, W.P., “A Simplified Reaction Mechanism for Soot Formation in Nonpremixed Flames," Combustion and Flame, 870 (3):289-305, 1991, ISSN 0010-2180, doi:https://doi.org/10.1016/0010-2180(91)90114-Q. URL http://www.sciencedirect.com/science/article/ pii/001021809190114Q.

19. Fraioli, V., Beatrice, C., and Lazzaro, M., "Soot Particle Size Modelling in 3d Simulations of Diesel Engine Combustion," Combustion Theory and Modelling, 150(6):863-892, 2011, doi: 10.1080/13647830.2011.578662. URL http://dx.doi.org/10.108 $\underline{0 / 13647830.2011 .578662}$.
20. Kronenburg, A., Bilger, R.W., and Kent, J.H., "Modeling Soot Formation in Turbulent Methane-Air Jet Diffusion Flames," Combustion and Flame, 1210(1):24-40, 2000, ISSN 00102180, doi:https://doi.org/10.1016/S0010-2180(99)00146-7. URL http://www.sciencedirect.com/science/article/pii/ $\underline{\text { S0010218099001467. }}$

21. Yao, T., Pei, Y., Zhong, B-J, Som, S. et al., "A Compact Skeletal Mechanism for n-Dodecane with Optimized SemiGlobal Low-Temperature Chemistry for Diesel Engine Simulations," Fuel, 191:339-349, 2017, ISSN 0016-2361, doi:https://doi.org/10.1016/j.fuel.2016.11.083. URL http:// www.sciencedirect.com/science/article/pii/ S001623611631184X.

22. Lucchini, T., D’Errico, G., Jasak, H., and Tukovic, Z.. Automatic mesh motion with topological changes for engine simulation," In SAE World Congress \& Exhibition, SAE International, Apr 2007, doi:10.4271/2007-01-0170. URL https://doi.org/10.4271/2007-01-0170.

23. Donde, P., Raman, V., Mueller, M.E., and Pitsch, H., "Les/pdf Based Modeling of Soot-Turbulence Interactions in Turbulent Flames," Proceedings of the Combustion Institute, 340 (1):1183-1192, 2013. ISSN 1540-7489, doi:https://doi. org/10.1016/j.proci.2012.07.055. URL http://www. sciencedirect.com/science/article/pii/S1540748912003471.

24. Bergin, M.J., Reitz, R.D., Oh, S., Miles, P.C. et al., "Fuel Injection and Mean Swirl Effects on Combustion and Soot Formation in Heavy Duty Diesel Engines," SAE Technical Paper 2007-01-0912, 04 2007, doi:10.4271/2007-01-0912. URL https://doi.org/10.4271/2007-01-0912.

\section{Acknowledgments}

This work was supported by the Swedish Energy Agency through project number 41043-1. The simulations were performed on resources provided by the Swedish National Infrastructure for Computing (SNIC) at HPC2N and PDC.

All rights reserved. No part of this publication may be reproduced, stored in a retrieval system, or transmitted, in any form or by any means, electronic, mechanical, photocopying, recording, or otherwise, without the prior written permission of SAE International.

Positions and opinions advanced in this paper are those of the author(s) and not necessarily those of SAE International. The author is solely responsible for the content of the paper.

ISSN 0148-7191 